\title{
Service Learning on an International Scale: The Experiences of Tufts University
}

\author{
Christopher W. Swan, Charline S. Han, and James F. Limbrunner \\ Tufts University
}

\begin{abstract}
There has been tremendous growth in the use of service learning in environmental engineering, especially in experiences beyond the U.S. This growth has been fostered by groups such as Global Village Engineers and Engineers Without Borders who seek to help communities in developing nations have a "better way" of life. Tufts University, long recognized for providing service to its host communities in Massachusetts, has also seen an increase in studentdriven initiatives that are beyond U.S. borders. Over the last year, students in the Department of Civil and Environmental Engineering at Tufts University have engaged in a number of projects in communities in Nicaragua and Ghana. This paper describes these projects, in terms of the engineering aspects, but also discusses the value these projects have in the education of the involved students. It is concluded that service learning projects, in general, provide a valuable pedagogical tool for educating future engineers.
\end{abstract}

\section{Introduction}

The mission statement of Tufts University states it will "offer to ...students a rigorous education ...that provides the knowledge and intellectual skills to become responsible and productive participants and leaders of society; ... to enhance learning and develop the potential of each student beyond, as well as within, the classroom; to encourage public service by students, faculty and staff, and to integrate service activities and experiential learning with teaching and research..." In order to implement this broad mission, the engineering curriculum must address both "hard" and "soft" aspects of environmental problems.

In engineering education, technical aspects needed to be an effective environmental engineer come from a variety of disciplines including engineering (civil, mechanical, chemical, etc.), natural sciences (geology, chemistry, physics, biology, etc.) and other specialized disciplines (microbiology, geochemistry, toxicology, etc.). However, effectively developing solutions to environmental problems often involves expertise in addressing non-technical aspects such as project management, communication, local and regional politics, economics, culture, and the social concerns of affected stakeholders.

For the past few years, the department of Civil and Environmental Engineering at Tufts University has used components of community-based service learning to enhance the learning experience of students in its environmental engineering curriculum ${ }^{2,3,4}$. All of these efforts have involved projects and/or curriculum involving local (Boston, MA area) communities. This paper highlights some of the ways community-based service learning, the pedagogy of combining education with community service, has been implemented in international communities. Specifically, the paper presents two projects in developing communities where the efforts of 
Tufts students and faculty have lead, and hopefully will continue to lead, to better living conditions for the affected communities.

\section{Background}

Community-based service learning (CSL) is a pedagogical tool helps students develop deeper appreciation of engineering as well as to communicate their engineering solutions to both a technical and lay audience. This pedagogical process forces students to consider both "hard" and "soft" constraints in environmental engineering analysis and design. For a number of years Tufts University has participated in various community-based projects, both extra-curricular and co-curricular. For example, a course on environmental site remediation evaluated small, urban brownfield sites in metropolitan Boston, MA that were undergoing, or needed to undergo remediation $^{2}$. Tufts is also a major partner in the Mystic Watershed Collaborative (MWC), a long-term partnership between the Tufts University Water Sustainability, Health, and Ecological Diversity (WaterSHED) Center, the Tufts Institute of the Environment, the Tufts University College of Citizenship and Public Service and the Mystic River Watershed Association $(\mathrm{MyRWA})^{1}$.

Expansion of CSL-based engineering education to international communities has only recently taken shape at Tufts. However, the value of these projects to the learning experience of the students involved has been significant and life-effecting. Below are summaries of two such projects and the effects they have had on the students involved.

\section{Kwabeng Ghana Schistosomiasis Project}

\section{Description}

An outbreak of schistosomiasis, a tropical disease carried by waterborne parasitic flatworms, occurred in the town of Kwabeng (population of 5,000) in the Eastern Region of Ghana, West Africa, primarily among school children. The disease, also known as Bilharzia, is particularly debilitating for children who are exposed to the flatworms in the muddy sediments of the nearby rivers. The World Health Organization estimates that 200 million people world-wide have schistosomiasis ${ }^{5}$. Children frequently go to the river to collect water, wash, and play. The reported symptoms of the children in Kwabeng include bladder infections, bloody urine, and anemia, which are consistent with the symptoms caused by Schistosoma hematobium.

The overall goal of our efforts is to greatly reduce (if not eliminate) the incidence of schistosomiasis and at the same time promote better management of water resources in the area. It was hypothesized that the presence and proliferation of the flatworms has been caused by changes to the hydrology and hydraulics of the local watershed, caused in large part by gold mining impoundments constructed within the watershed. As part of their senior capstone project, a six-student group developed a set of possible solutions for controlling schistosomiasis in Kwabeng. The three major categories of interventions include: (1) controlling the parasite population that enter the snails, (2) controlling the intermediate host (snails), and (3) providing alternatives to using the river water. The interventions within these categories were evaluated on five criteria: cost, feasibility, community acceptance, efficacy, and sustainability. Based on their work, the best correction actions for implementation in Kwabeng were (1) increase river velocity by river restoration to reduce the snail population, (2) community-wide education campaign on alternative potable and recreational water management, and (3) monthly schistosomiasis screening and treatment days. Their work comprised of an initial characterization of the nature, complexity, and boundaries of the problem. 


\section{Reflection}

Below is the personal reflection of one of the group members, Charline Han.

"After becoming better acclimated to the culture, food, time change, and heat in Accra (Ghana's capital), we began our work in the more rural town of Kwabeng. Driving to Kwabeng was eye-opening for everyone. We were finally leaving the hustle and bustle of the urban capital where any foreigner could obtain all of the amenities of a western life for less than half the price. For me, it was nice to get out of the city life and into the more rural town, where life is slower and the people and culture have been untouched by international influences. Upon arriving in Kwabeng, we were greeted by our host family with the sincerity and warmth that is so unique to Ghanaian culture. After brief introductions, we took a walk around the town in order to become better acquainted with the watershed. It was a relief to finally see the town, the river, and its people after all of the discussions held in the 5 months prior to our visit. The people were especially friendly and the commencement of the project seemed hopeful and exciting. But of course, observing the problem on site brought light to the fact that nothing is quite as it seems from across the Atlantic.

From Tufts, the project seemed a lot more objective, and almost hypothetical. But after arriving in Kwabeng, you suddenly get pulled into the project in so many different ways. I think the difference in perceptions is mainly attributable to the interactions with the people in Kwabeng. It's a unique experience to be working with something so real, and the impact of the disease is very evident. The people are very aware of the work done by the mining company and the hydraulic changes to the river that have resulted. Most, if not all, of our historical data about the watershed pre-mining came from talking with community members. Without the interactions with the people, our data set would have been incomplete. The information that we obtained from conversations and interactions with community members could never have been found in any textbook nor could it have ever been predicted or assumed with our prior knowledge of the situation. Observing this problem first-hand introduced a new dimension to the engineering education we had received in the U.S. Suddenly we were faced with a new challenge of integrating all that we had learned from our engineering curriculum into a real-life problem immediately surrounding us.

A description of our first full day of work in Kwabeng provides a snapshot of the many barriers we would encounter. We started the day by delegating roles, and it was nice to finally get started on our work. We had set up a small lab station on the front porch of one of Kwabena's relatives' house and it was sure to attract a crowd of ten to fifteen children at any given point in the day to observe and stare at the make-shift lab station we had set up. We set up a light microscope and gathered all of our water quality and water velocity measuring equipment on the porch. We were all very hard at work, but working all day had not proven to be as productive as we had thought or had hoped. For one, it just so happened to be the first day of rain in a month since it was the dry season and it was raining extremely hard. So instead we had a series of meetings with the town Elders and the town King. We handed out some flyers that we made describing our project and our goals and provided brief introductions for ourselves. Kwabena served as our translator. We were a little bit intimidated by the meeting with the town King, 
because the King and his team of people were not only dressed in the traditional royal clothing, but they also practiced their traditional royal customs when greeting new people and communicating through linguists. After our meetings, we spent the rest of the day working indoors because of the rain, but with frequent power outages, were stuck with headlamps and very slow progress on the objectives we had wished to accomplish. Our planned schedule from that point forth became increasingly complicated since so many things depended on so many other things - rain, other peoples' schedules, business hours, functioning of equipment, power outages, etc.

By the fourth or fifth day, we were fully adjusted to the consistently inconsistent schedules and unreliability of weather, power, and other people. Even our visit to the library at the University of Ghana was discouraging. Without electronic card catalogs or any comprehendible organization system by subject, our expectations for finding a wealth of medical, geographic, and environmental information in-country were not met. But we did realize that we had more work than even our ten day trip would allow us to complete.

The rest of our time there consisted of tours of the watershed to create a detailed georeferenced map of the town, water sample collections to determine schistosome and snail counts per unit volume of water, velocity measurements of various locations of the river, and daily meetings with community members (including farmers, school teachers, school children, and elders). There was more than enough work for just the six of us and we determined that the best method was to divide into sub-teams. Each day began with a delegation of roles and assignments for each member of the team, and each day ended with story telling about each of our failures and physical exhaustion from the sun. It was interesting to see the looks on everyone's faces when we congregated at the end of each day to discuss the accomplishments and failures of each of our efforts.

The whole experience proved to be very physically, as well as mentally and emotionally, demanding. It was apparent through our nightly conversations within the group of students that we were all greatly impacted by the magnitude of this health problem on this community and its people. What made the impact even more profound was observing the way of life of these people and their perception of the problem. Many of the children were more interested in the way our digital cameras or GPS units worked rather than the blood that was coming through their urine. And others were more enthusiastic about the picture we would take with the classroom than the implications of the health survey they were about to take. Something is to be said about the people's abilities to maintain their curiosity and inquisitiveness in our lives while a major health outbreak is being explored in their lives. But I think it was this inquisitiveness and their constant smiles that provided the most energy for us and our work during our time in Kwabeng."

\section{Siuna, Nicaragua Medical and Water Resources Assessment \\ Description}

Siuna, Nicaragua, is a municipal region in northeastern Nicaragua, known sometimes as

the "Mining Triangle" because of a history of gold mining in the region. There are about 18,000 people living in a $2 \mathrm{~km}^{2}$ urban section, divided into 17 neighborhoods, and an additional 56,000 people living in 133 rural communities in the $5,162 \mathrm{~km}^{2}$ that makes up the municipality of Siuna. It is a very poor region of Nicaragua, separated politically and geographically from the more developed Pacific coast and from the seat of the national government in Managua. It takes 
about 12 hours to drive from Managua to Siuna, and since much of the road between the two cities is unpaved, the route is often impassible during the rainy season. Only $10 \%$ of Siuna's population is employed in the formal economy; average monthly per capita income is US\$24, and over $83 \%$ of the population lives in extreme poverty. Historically, natural resources such as timber and gold have been the region's major products, but these have been extracted by foreign companies and have resulted in little benefit to the local population. Presently, Siuna is primarily a ranching community, where forests are cleared for livestock

An interdisciplinary team of Tufts medical students and staff, a veterinarian, and a graduate student from the School of Engineering traveled to Siuna, Nicaragua for a field service project. They worked in conjunction with a non-profit organization called Bridges to Community to provide medical and water resource assessment services during the trip. The region's population suffers from many forms of poverty, including lack of adequate health care and potable water infrastructure, and elevated concentrations of heavy metals in soil, likely due to the historic gold mining operation. Present agricultural practices involve slash and burn of forested areas that lead to environmental degradation including erosion and impacts to local water supply reservoirs. Much of the region's domestic water supply comes from untreated surface water and shallow dug wells that are probably contaminated with pathogens. The team's water resources assessment involved talking with public officials and professors at a local college, reviewing technical documents, field visits to water supply system components, and water quality sampling.

\section{Reflection}

The following is a personal reflection by the involved student, James Limbrunner.

"The experience in Nicaragua has been very important to me since many of the problems we face, both here and abroad, require much more than technical solutions. If as engineers we can apply our knowledge in an interdisciplinary and collaborative way, we may not only help solve the compelling problems of development, but also may expand the applicability and positive influence of the engineering profession. Working in a developing country presented us with problems that were different and challenging, and required us to apply creatively the skills we learn in the classroom. With location, language, culture, and living conditions all different from our usual experiences, the sense of adventure, and the chance to learn were large.

On last year's trip, I gained technical experience in assessing water resources, but more importantly, I was exposed to a world with which I was very unfamiliar. I will always remember my first trip though the town of Siuna, riding in the back of a pick-up truck, over dusty roads, trying to grasp the vast difference between the sights, smells and sounds of my new location with those I had recently left behind in Boston. I've gained valuable awareness of the realities faced by many people who live in low-income countries, an appreciation for comforts at home that I took for granted, and a desire to help Nicaraguans develop those comforts if they want them. I think engineering students need the technical training of traditional engineering programs, but we also need the supplement of broadening experiences like this, so we understand better how our work fits into larger contexts, like development and poverty reduction.

This year, we designed a protocol to collect water samples from rivers and shallow dug wells, and to measure E. coli concentration. Developing methods for filtration and incubation in the field, without electricity, gave us practice in creative 
thinking that will hopefully be typical of our future careers. We hope to share our method with students at the college in Siuna, by inviting them to join us during sampling and analysis activities, and by discussing our findings with them, both for their benefit and for ours. As foreigners, it is difficult for us to truly understand the needs and desires of Siuna's residents, but we might help by suggesting tools that may be useful to them, and we can learn from them about different ways of approaching universal human problems, like water supply and pollution.

While working on the projects, we've had a chance to practice non-technical professional skills such as logistics and coordination, communication, handling changing conditions, and interdisciplinary teamwork. The projects in Nicaragua have involved students and faculty from the medical, veterinary, and engineering schools, building links that have added richness to our educational experiences. In the developed world, there is not often opportunity for professionals from many different disciplines to work closely together on a single problem, since much of the interaction among professions is masked by a highly developed system in which each specialist concentrates on a single aspect of a larger problem. This keeps doctors in hospitals and engineers at drafting boards, without much interaction. However, when working together in a developing region that lacks basic infrastructure like hospitals and drafting boards, we were exposed to the necessity and interrelatedness of each of our disciplines, and we gained a sense of how environmental engineering and medicine operate together to promote health. The close exposure to other professional cultures was as interesting to me as the exposure to another human culture, and the long, candle-lit evenings gave us much opportunity to talk and to reflect on the day's events, to share perspectives, and to visit with residents of Siuna.

In the coming year, I hope to continue my connection with Nicaragua. A possible project would be to collect rain water for drinking and hand washing at a school, combining engineering, public health, and education components. Since physical infrastructure is likely to be helpful only if there is also local capacity to maintain and operate it, we hope to contribute to developing that capacity. The rainwater collection system would be intended for use by Nicaraguan educators as a teaching tool to instruct children regarding data collection, water supply, and basic hygiene. Early lessons for children who will become future stewards of their natural and infrastructural resources could be helpful in developing the social system necessary to support physical infrastructure.

Siuna is located adjacent to the 750,000 hectare Bosawas Reserve, a dense undisturbed rain forest. Faculty and students from Tufts' veterinary school and engineering school are discussing the potential for collaborating to study the effects of alternate land use and animal management practices on ecological health in the reserve's buffer zone, with the intent to develop analysis tools useful to Nicaraguans as they work to manage their resources.

The field practice, the opportunity for interdisciplinary teamwork, and the development of ongoing projects have been very exciting for me as an engineering student, and an important part of my education. My experiences in Nicaragua have also been of great personal value, because of new friends, a deeper understanding of the problems faced by people in developing countries, and a better sense of positive applications for the engineering skills I'm learning." 


\section{Discussion}

Though each student worked in a very different region, they both comment on similar experiences regarding application of engineering skills to real problems with added complexity from unfamiliar locations, cultures, and resources. They comment about the challenges of changing conditions, the lack of electricity, and compelling health and humanitarian issues to which they were exposed. The "out of comfort zone" opportunity provided by an international service learning experience appears to have been thought-provoking for the students as they comment on both social and technical issues encountered in their travels, and they appear to be thinking more about how they fit into a broader world on both professional and personal levels. The personal growth afforded by a service learning experience is likely to serve them well as future professionals and global citizens.

\section{Conclusions}

The synergistic effects of combining environmental engineering with CSL-based pedagogy are evident in the enhanced education received by both students (and associated faculty) and the new spirit of collaboration developed between participating communities and the university. For example, a number of benefits to student learning are evident.

1. Traditional design pedagogy plus CSL provided students complimentary vehicles in which to refine their designs in ways that deepened their understanding and learning.

2. The added value of CSL in student education forces students to recognize that all aspects of design (hard and soft) are important.

3. Use of CSL oriented projects causes students to "think outside the technical box" to develop appropriate and realistic environmental designs.

4. Students come to realize that professional and social responsibilities go together.

\section{Acknowledgements}

The authors would like to thank the Tufts University and the many centers and departments for their past and continuing support in helping establish these community ties.

\section{Bibliography}

1. Kirshen, P., Durant, J., Perez, G., "Water Resources Management in the Mystic River Watershed II: University and Community Collaboration through Service Learning and Active Citizenship", Watershed Management 2000, American Society of Civil Engineers, 21-23 June 2000, Fort Collins, CO.

2. Swan, C., Rachell, T., and Sakaguchi, K. "Community-Based, Service Learning Approach to Teaching Site Remediation Design”, 2000 ASEE Annual Conference and Exposition, June 2000, St. Louis.

3. Swan, C., Kirshen, P., and Durant, J. "Environmental Engineering Education and Community Service: A Synergistic Partnership", 2002 ASEE Annual Conference and Exposition, June 2002, Montreal. Louis.

4. Swan, C. (2004) "Case Study of a Project for First-Year Students that Integrates Research and Community Service", 2004 ASEE Annual Conference, June 2004, Salt Lake City

5. World Health Organization. Fact Sheet No. 115. May 1996 


\section{CHRISTOPHER W. SWAN}

Dr. Swan is an Associate Professor in the Civil and Environmental Engineering department at Tufts University. His current interests are the reuse of recovered or recyclable materials and sustainable construction.

\section{CHARLINE S. HAN}

Ms. Han is a current MS graduate student in the Civil and Environmental Engineering department at Tufts

University. She also received a BS in Environmental Engineering from Tufts and will be pursuing a MD from Tufts University Medical School starting in Fall 2006.

\section{JAMES F. LIMBRUNNER}

Mr. Limbrunner is a current $\mathrm{PhD}$ graduate student in the Civil and Environmental Engineering department at Tufts University. He also received BS and MS degrees in Civil Engineering from Tufts. His teaching and research interests lie in the areas of water resources, sustainable development and appropriate technologies. 